\title{
Postpartum intrauterine contraceptive device: effect of antenatal versus postpartum counselling in acceptance of postpartum intrauterine contraceptive device
}

\author{
Monika Raghuwanshi, Sonal Agrawal*, Beenu Kushwah Singh, Neha Khatik
}

Department of Obstetrics and Gynecology, Shyam Shah Medical College Rewa, Madhya Pradesh, India

\author{
Received: 24 June 2020 \\ Accepted: 01 August 2020 \\ *Correspondence: \\ Dr. Sonal Agrawal, \\ E-mail: raghuwanshi.monika10@gmail.com
}

Copyright: () the author(s), publisher and licensee Medip Academy. This is an open-access article distributed under the terms of the Creative Commons Attribution Non-Commercial License, which permits unrestricted non-commercial use, distribution, and reproduction in any medium, provided the original work is properly cited.

\begin{abstract}
Background: The acceptance for postpartum intrauterine contraceptive device (PPIUCD) in our country, especially in rural areas is very low despite all the efforts. Counselling during the antenatal visits may play a vital role in improving the acceptance of PPIUCD. Objective of this study was to assess the factors associated with the acceptability of immediate PPIUCD insertion in women; counselled during antenatal and postpartum period; according to their sociodemographic and obstetric characteristics, and future pregnancy desires.

Methods: One-year prospective study carried out in the department of obstetrics and gynecology, S. S. Medical College Rewa, Madhya Pradesh, India. a total of 4850 women were counselled for PPIUCD insertion; 2540 during their antenatal visits, and 2310 during postpartum period who visited in study centre for first time and their follow up was done. Chi square tests were applied to compare proportions.

Results: After antenatal counselling in 2540 women, (with multiple counselling sessions) about half of the women gave verbal acceptance for PPIUCD. However, during postpartum counselling in 2310 women, (where only single short session of counselling could be done) majority of the women declined (80.9\%) for PPIUCD insertion with only about a fifth $(19.1 \%)$ of the women giving verbal acceptance. Women who had antenatal counselling one third of them had PPIUCD insertion. In the postpartum counselling group, a meagre $15.1 \%$ women had PPIUCD insertion.

Conclusions: Counselling during antenatal and postpartum period is the key to improve the awareness and acceptance of PPIUCD in our community. Multiple counselling sessions during antenatal visits make it easier for the women to slowly understand the process and accept PPIUCD as compared to the short counseling during postpartum period.
\end{abstract}

Keywords: Antenatal counselling, Postpartum intrauterine device, Postpartum intrauterine contraceptive device

\section{INTRODUCTION}

WHO recommends a birth to pregnancy interval of minimum 2 years to have a better maternal and foetal outcome across developing and developed countries. ${ }^{1}$ Post-partum family planning is currently focused by WHO and government of India to prevent unwanted and closely spaced pregnancies. These closely spaced pregnancies are major causes of maternal, infant and child mortality. These pregnancies are not only the cause of population growth but also put a huge load on the health care system. Pregnancies with short interpregnancy interval are associated with increased risk of maternal and fetal morbidity and mortality; like increased chances of preterm/ low birth weight babies, increased risk of spontaneous abortions and induced abortions of unwanted pregnancies, nutritional deficiencies in lactating pregnant mothers. ${ }^{2-4}$ After delivering a child in a health care facility woman are busy in nursing of the baby, It difficult for them to visit a 
health care centre, as most women belong to remote and rural settings; and the transportation charges may be burdensome to many of them. Due to these and many more reasons the contraception use rate of postpartum females is much less. ${ }^{5}$

Generally, contraception is discussed at 6 weeks postpartum but fertility of the females returns earlier in females who are not exclusively breast feeding, and there is evidence that $35-57 \%$ females resume intercourse within 6 weeks postpartum so there are higher chances of unintended pregnancies in these females. ${ }^{6,7}$ The time after delivery and before leaving the hospital provides a window of opportunity for the health care provider to introduce a method of contraception of choice to the female.

\section{IUCD}

World-wide over $14 \%$ of married women use IUCD. In united states it is estimated that $6.4 \%$ women use IUCDs. ${ }^{8}$ In our country according to NFHS 4 data the IUCD usage is only $2.7 \%$ of overall contraception usage and only $1.5 \%$ of overall currently married women (15 to 49 years age group) use IUCD. ${ }^{9}$ All IUCDs are safe, long term contraception with effectiveness equivalent to tubal sterilization.

In the postpartum females who are in need for spacing but want pregnancy later on, a non-hormonal long acting reversible contraceptive-copper containing intrauterine device, is the ideal method of choice. It is the most effective and one of the good options for spacing pregnancies.

Postpartum period is critical for 2 reasons: these women has a need for contraception; and have multiple contacts with the health facility either for postnatal visits or child immunization. Intrauterine contraceptive device (IUCD) is the ideal and most effective option for contraception in the immediate postpartum period. It is convenient, long acting and highly reversible. ${ }^{10}$ It does not interfere with lactation and the common menstrual problems do not occur in immediate post-placental period as women have lactational amenorrhea during this period. ${ }^{11}$ The expulsion rates are also minimal when it is inserted by a trained healthcare provider and when placed at fundus. ${ }^{12}$

PPIUCDs are still emerging as relatively new contraception choice in India. Despite making PPIUCD widely available, the acceptance for PPIUCD is low probably due to lack of awareness, fear of complications and ignorance among clients. Acceptance of PPIUCD can be increased by counselling and education.

While follow-up data is available from international and urban India sources, given the scale at which PPIUCD services are being introduced in India, it was important to generate evidence from rural setting on the post insertion outcomes after the introduction of PPIUCD program.
Additionally, information related to demographic profile of women who accept PPIUCDs, their dynamics of decision-making process, their satisfaction with this method, and complications of PPIUCD have not been well characterised. In this context, authors planned to conduct a prospective study of a large cohort of women in rural part of Madhya Pradesh, who received or denied PPIUCD.

\section{METHODS}

One-year prospective study carried out in the department of obstetrics and gynecology, Gandhi Memorial Hospital, Shyam Shah Medical College, Rewa, Madhya Pradesh, India.

One year from January 2018 to December 2018 for recruitment, counselling and PPIUCD insertion.

\section{Inclusion criteria}

Inclusion criteria of this study were pregnant women attending antenatal OPD of Gandhi memorial hospital Rewa. Full-term pregnant women who have delivered; whether vaginally or cesarean section; in obstetrics and gynecology department of GMH Rewa irrespective of baby outcome. Singleton or multiple pregnancy. $\mathrm{Hb}>9$ $\mathrm{g} \%$.

\section{Exclusion criteria}

Exclusion criteria of this study were women who have a history of purulent cervicitis in antenatal period, chorioamnionitis, purpureal sepsis, more than 18 hours of rupture of membrane, unresolved postpartum hemorrhage, extensive genital trauma, known distorted uterine cavity; like uterine septum, fibroid uterus. High individual likelihood of exposure to gonorrhea or chlamydia. Malignant or benign trophoblastic disease. Suffering from HIV-AIDS (who is either clinically unwell or not on anti-reteroviral therapy).

\section{Methodology}

In antenatal OPD, women coming in their $1^{\text {st }}, 2^{\text {nd }}$ and early $3^{\text {rd }}$ trimester were explained regarding the purpose of study in order to obtain their consent whether they wanted to participate or not. Those who agreed to participate in the study and were found to fulfil the inclusion criteria were provided with a structured openended questionnaire, it included socio-demographic factors, antenatal history, awareness of PPIUCD and reasons for acceptance and rejection among study members.

Women were further called after 1 month and were asked to submit back the completed questionnaire, if any of the participants had any doubt, they were cleared accordingly and were told to reconsider their options. 
Antenatal care was provided as per standard norms and participants were advised to bring their tagged antenatal cards at the time of delivery.

All women who came for first time during their delivery (latent phase) and were found to fulfil the inclusion criteria were recruited for the study after taking informed consent and were counselled regarding PPIUCD insertion.

A total of 4850 females were recruited for PPIUCD insertion, who visited and delivered in department of obstetrics and gynecology department of Shyam Shah Medical College Rewa; and informed consent was taken from them. Out of the 4850 females; 2540 visited the antenatal OPD and their follow up was done; and 2310 visited the labor room for the first time for their delivery, without any prior antenatal visits. All of these women were counselled for PPIUCD insertion.

\section{Antenatal counselling}

Counselling for postpartum family planning and PPIUCD insertion and other methods was given to 2540 low-risk women in the antenatal OPD in their 2 or more visits. Each client was counselled individually, this method ensured that the clients made voluntary, informed and well considered choice. 1630 women gave verbal acceptance for PPIUCD insertion after counselling and 910 women declined; many were lost during follow up period. 881 women who came for delivery in our institute and were again asked for PPIUCD insertion. In these 881 women, the actual insertion of PPIUCD was in 660 women and 221 declined at the time of insertion. All the reasons for acceptance and refusals were recorded.

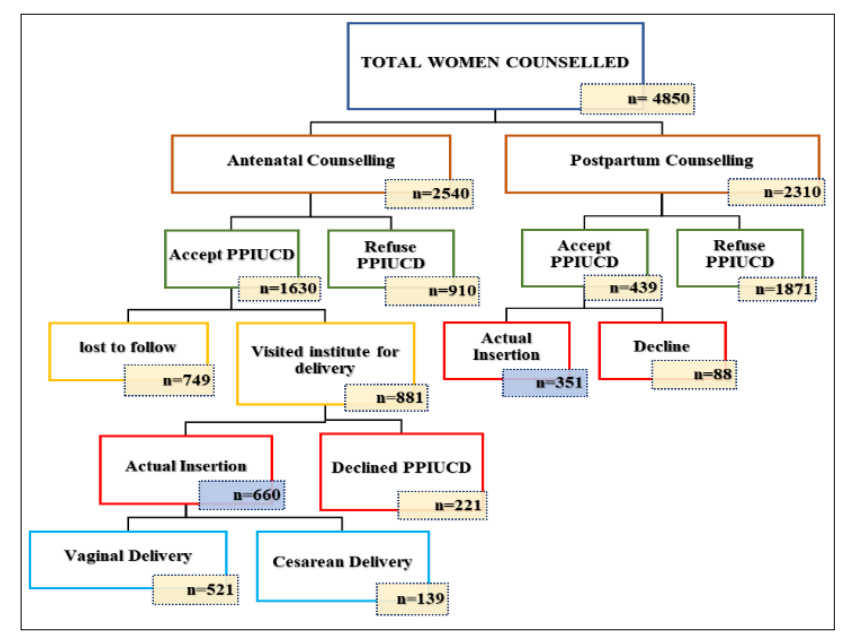

Figure 1: Process of recruitment of final study population.

\section{Postpartum counselling}

Counselling for postpartum family planning after vaginal delivery was given to 2310 females visiting the labour room of Gandhi Memorial Hospital Rewa. Counselling was done when the patient rested sufficiently, but before discharge from the institute. 439 females accepted and 1871 clients declined for PPIUCD insertion. Of these 439 clients, 351 had actual insertion of PPIUCD within 48 hours of vaginal delivery and 88 declined at the time of insertion. The reasons for acceptance and refusal were again recorded (Figure 1).

All the data was collected and was analysed using statistical package for social sciences (SPSS version $23^{\text {rd }}$ ). Pearson's chi square test was used to determine whether there was a significant difference in the expected frequencies and the observed values, and to find the association between variables. The confidence interval was taken to be $95 \%$, and $\mathrm{p}$ value of $<0.05$ was taken significant.

\section{RESULTS}

All the women attending the antenatal OPD and those coming for delivery in our hospital were explained about the study; and amongst them, who gave consent to participate in the study were recruited.

Table 1: Age distribution of initial study population.

\begin{tabular}{|lll|}
\hline Age (in years) & Frequency (n) & Percentage \\
\hline $\mathbf{2 0}$ & 242 & 4.9 \\
\hline $\mathbf{2 1 - 3 0}$ & 2813 & 58.1 \\
\hline $\mathbf{3 1 - 4 0}$ & 1647 & 33.9 \\
\hline $\mathbf{> 4 1}$ & 148 & 3.1 \\
\hline Total & 4850 & 100 \\
\hline
\end{tabular}

In this study most women participating belonged to 21-35 years age group as this study is confined to the women in their reproductive age group (Table 1).

Table 2: Education status of initial study population.

\begin{tabular}{|lll|}
\hline Education & Frequency (n) & Percentage \\
\hline Illiterate & 1187 & 24.4 \\
\hline Primary school & 2283 & 47.1 \\
\hline Secondary school & 1110 & 22.9 \\
\hline Formal education & 270 & 5.6 \\
\hline Total & 4850 & 100.0 \\
\hline
\end{tabular}

Table 3: Socioeconomic status of initial study population.

\begin{tabular}{|lll|}
\hline Socio-economic status & $\begin{array}{l}\text { Frequency } \\
\text { (n) }\end{array}$ & Percentage \\
\hline Lower class (V) & 1792 & 36.9 \\
\hline Upper lower class (IV) & 2286 & 47.2 \\
\hline Lower middle class (III) & 458 & 9.4 \\
\hline Upper middle class (II) & 222 & 4.6 \\
\hline Upper (I) & 92 & 1.9 \\
\hline Total & 4850 & 100 \\
\hline
\end{tabular}


Majority of women in this study belonged to low socioeconomic strata, as evident that almost three fourth population, had not attended secondary school, they were educated till primary school or were illiterate and belonged to lower and upper lower class of socioeconomic group (Kuppuswamy scale 2019) (Table 2 and 3). Only about one fourth women had formal or secondary school education. This type of clientele requires increased effort in emphasizing contraception as prevention for future pregnancy that may help to decrease maternal morbidity and mortality.

\section{DISCUSSION}

In the study by Achyut et al women participating in their study had similar sociodemographic characteristics; $40.7 \%$ women belonged to age group of 25-29 years; and around $50 \%$ of their study population had lower SES (socio economic status); about $45 \%$ women had no education or had went to only primary school with only 1-7 years of schooling. ${ }^{13}$ Education has a positive effect on PPIUCD/ contraceptive use as was shown in a study conducted in Zimbabwe by Thomas et al, that was apparent among women who completed secondary education (12 years or more). ${ }^{14}$ In this study women who had completed secondary school are twice as likely to adapt a modern method of contraception as women who did not complete primary education.

In this study authors first found that about $75 \%$ women had an awareness regarding PPIUCD (Table 4), but when authors look at the data regarding their source of information (Table 5) only about half of these 'aware' women had a proper source of information like a health care provider, ASHA or by school education. Rest of the women have heard about PPIUCD by their neighbours, relatives or they don't remember about their source of information. If authors remove the unreliable sources of information, the awareness level was found to be in only around $40 \%$ women and rest $60 \%$ women had no proper source or no awareness at all. This is the group of females who have misconceptions and myths regarding PPIUCD as they believe in what they are told by someone they trust.

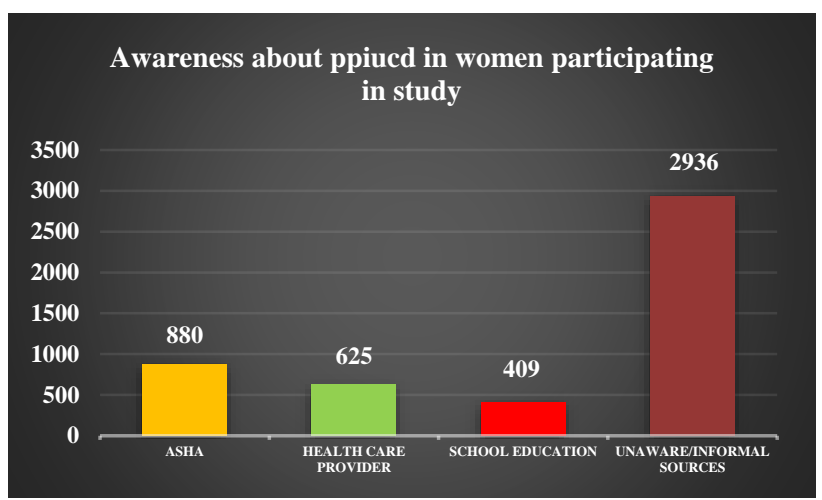

Figure 1: Actual awareness about PPIUCD.

Table 4: Awareness about PPIUCD in initial study population.

\begin{tabular}{|lll|}
\hline $\begin{array}{l}\text { Awareness about } \\
\text { PPIUCD }\end{array}$ & $\begin{array}{l}\text { Frequency } \\
\text { (n) }\end{array}$ & Percentage \\
\hline Yes & 3682 & 75.9 \\
\hline No & 1168 & 24.1 \\
\hline Total & 4850 & 100 \\
\hline
\end{tabular}

Table 5: Source of information about PPIUCD in initial study population.

\begin{tabular}{|lll|}
\hline Source of information & Frequency (n) & Percentage \\
\hline Neighbours/relatives & 1328 & 36.1 \\
\hline Asha & 880 & 23.9 \\
\hline School education & 409 & 11.1 \\
\hline Health care provider & 625 & 17.0 \\
\hline Don't remember & 440 & 11.9 \\
\hline Total & 3682 & 100 \\
\hline
\end{tabular}

Table 6: Verbal acceptance and refusal at the time of counselling (excluding women who were lost to follow-up).

\begin{tabular}{|c|c|c|c|c|}
\hline Women counselled for PPIUCD insertion & $\begin{array}{l}\text { Antenatal } \\
\text { counselling }\end{array}$ & $\begin{array}{l}\text { Postpartum } \\
\text { counselling }\end{array}$ & Total & P value \\
\hline Gave acceptance for PPIUCD & $881(49.2)$ & $439(19.1)$ & 1320 & \multirow{3}{*}{$\begin{array}{l}\chi^{2}=421.45 \\
D F=1 \\
P=<0.05\end{array}$} \\
\hline Declined at the time of counselling & $910(50.8)$ & $1871(80.9)$ & 2781 & \\
\hline Total & 1791 & 2310 & 4101 & \\
\hline
\end{tabular}

Chi square $=421.45$, Degree of freedom $=1, \mathrm{P}=<0.05$ Significant.

Table 7: Actual insertion of PPIUCD among total counselled women.

\begin{tabular}{|c|c|c|c|c|c|}
\hline \multicolumn{2}{|c|}{ Women counselled for PPIUCD insertion } & $\begin{array}{l}\text { Antenatal } \\
\text { counselling }\end{array}$ & $\begin{array}{l}\text { Postpartum } \\
\text { counselling }\end{array}$ & Total & \multirow{3}{*}{$\begin{array}{l}\text { P value } \\
\chi^{2}=424.89 \\
D F=2\end{array}$} \\
\hline Actual in & ertion & $660(36.8)$ & $351(15.1)$ & 1011 & \\
\hline \multirow{2}{*}{ Declined } & At the time of insertion & $221(12.4)$ & $88(3.8)$ & 309 & \\
\hline & During counselling & $910(50.8)$ & $1871(80.9)$ & 2781 & $\mathrm{P}=<0.05$ \\
\hline \multicolumn{2}{|l|}{ Total } & 1791 & 2310 & 4101 & \\
\hline
\end{tabular}

Chi square $=424.89$, Degree of freedom $=2, \mathrm{P}=<0.05$ significant. 
Table 8: Insertion of PPIUCD among total participants who gave verbal acceptance for PPIUCD insertion.

\begin{tabular}{|lllll|} 
Women counselled for PPIUCD insertion & $\begin{array}{l}\text { Antenatal } \\
\text { counselling }\end{array}$ & $\begin{array}{l}\text { Postpartum } \\
\text { counselling }\end{array}$ & Total & P value \\
\hline Actual insertion & $660(74.9)$ & $351(79.9)$ & 1011 & $\chi^{2}=4.15042$ \\
\hline Declined at the time of insertion & $221(25.1)$ & $88(20.1)$ & 309 & $\mathrm{DF}=1$ \\
\hline Total women (who gave acceptance) & $881(100)$ & $439(100)$ & 1320 & $\mathrm{P}=0.04(<0.05)$ \\
\hline
\end{tabular}

Chi-Square $=4.15042$, Degrees of freedom $=1, P=0.0416242$.

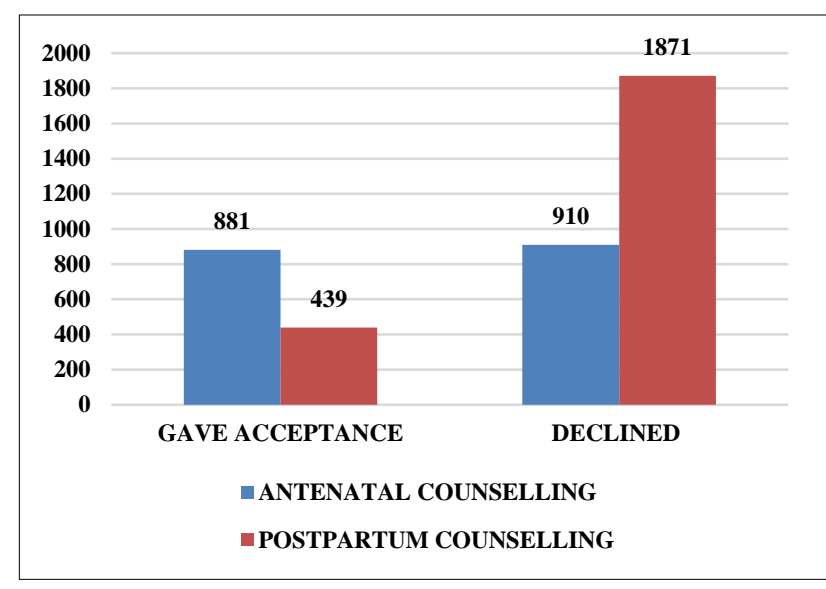

Figure 2: Acceptance and refusal at the time of counselling.

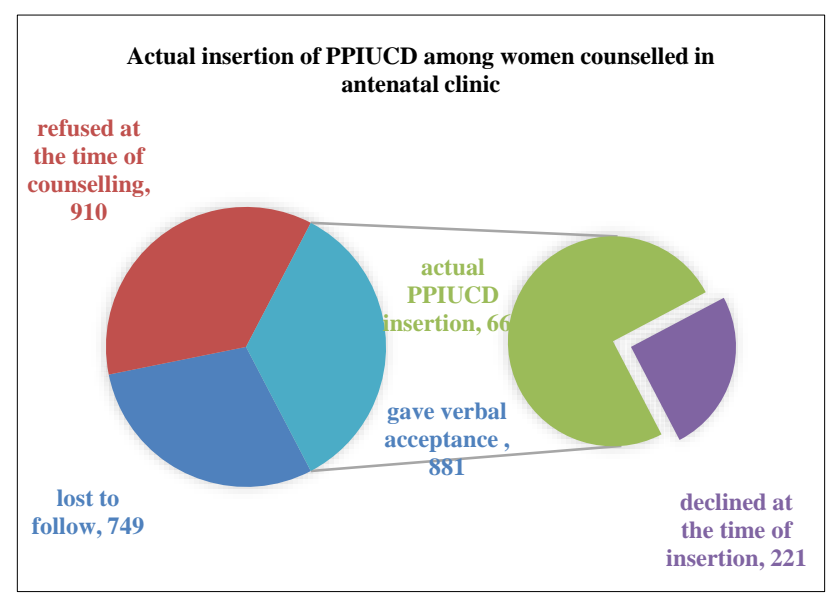

Figure 3: Actual insertion of PPIUCD in women during antenatal counselling.

In a study conducted by Vallippan A et al, they addressed the level of knowledge about PPIUCD. ${ }^{15}$ They concluded that exposure to formal health counselling were factors that affected the level of knowledge and exposure to health care education and prior discussion with husband/family can improve the knowledge and likelihood of acceptance of PPIUCD. Similar results were found in a study by Nigam et al in New Delhi India that awareness of PPIUCD was low leading to high refusal rates $(48 \%$ were aware about $\mathrm{Cu}-\mathrm{T}$ but only $21.9 \%$ had knowledge about PPIUCD). ${ }^{16}$ The commonest cause of refusal was lack of proper counselling and; not only women but husband and mother in law must be provided with knowledge as they play an important role in our society.

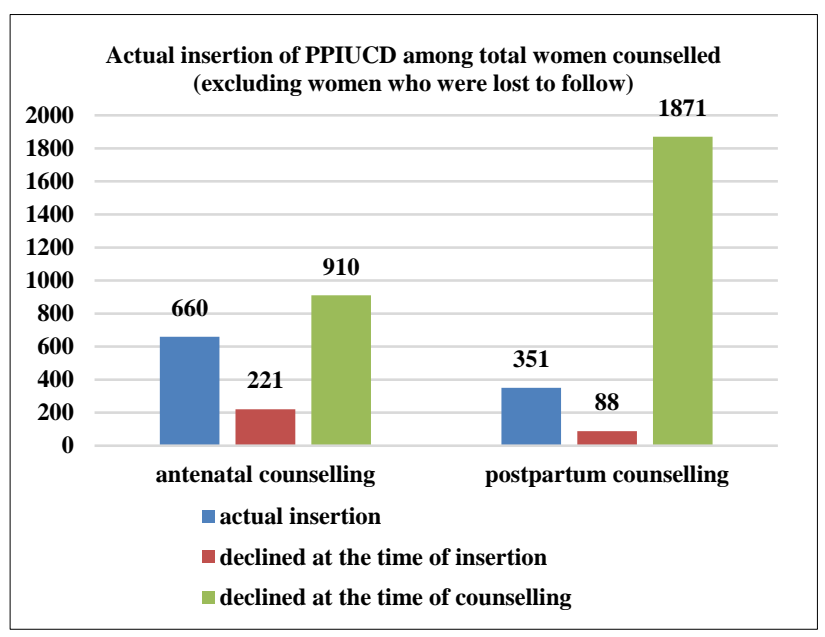

Figure 4: Actual insertion of PPIUCD among total participants who gave verbal acceptance for PPIUCD insertion.

In this study authors found that when patients are counselled during their visits in antenatal OPD and after multiple sessions of counselling the acceptance rate of PPIUCD was found to be much higher (49.2\%) than a single short counselling during their postpartum period $(19.1 \%)$, this result was found to be statistically significant with $\mathrm{p}<0.05$ (Table 6). As with counselling during antenatal visits, with multiple counselling session these women were able to discuss more freely and stress free and had ample amount of time to decide whether they want to opt for a method of contraception. WHO has included family planning counselling in ANC care. ${ }^{17}$

Cleland $\mathbf{J}$ et al in their study found evidence form several countries that multiple family planning counselling during antenatal period led to major increase in postpartum contraception uptake, whereas single short counselling had no impact. ${ }^{18}$ This result is also supported by a study conducted by Agrawal $\mathrm{N}$ et al in Uttar Pradesh India found that the patients counselled during their antenatal period had higher acceptance of PPIUCD $(43.9 \%)$, than un-booked women who were counselled during their postpartum period $(23.4 \%) .{ }^{19}$ 
In this study the insertion rate was $36.8 \%$ in antenatal counselling and $15.1 \%$ in postpartum counselling, which was statistically significant (Table 7); around 20-25\% women in both groups declined at the time of insertion after giving consent at the time of counselling (Table 8). It was slightly more amongst women who gave consent for insertion during their antenatal counselling as compared to postpartum counselling but the difference was statistically significant. The reasons are not fully clear but plausible explanation might be the exhaustion after the delivery and husband or family refusal or the 'newness' of PPIUCD in community. In this study only a quarter of counselled women had PPIUCD insertion $(24.65 \%)$ (Table 8).

Similar results were found by Gautam et al (acceptance rate $21 \%$ ), Kathpalia et al (about 18\%) and in Gonie et al (about 16\%) but was lower than this study. ${ }^{13,20,21}$ In other studies, the acceptance for PPIUCD was even lower. In the study by Valliappan et al only $8.5 \%$ women accepted PPIUCD. ${ }^{15}$ The possible reason might be that in these studies they did not include counselling the women prior to PPIUCD insertion. The reasons for low acceptance might also be the low educational status of the patients, age of last child or their parity which are discussed below.

\section{CONCLUSION}

On the basis of the available literature and results of the index study, which substantiate the earlier findings, it can be concluded that:

Insertion of IUCD in the immediate postpartum period is an effective, safe and convenient contraception in the immediate postpartum period. The awareness and acceptance of PPIUCD is still very low in our society. Women who belong to lower socioeconomic strata and women with low educational status are the ones who generally have myths and misconceptions regarding PPIUCD; and counselling during antenatal visits and postpartum period is the ideal time for recruiting these women for PPIUCD insertion, as during this time the women is already in the health care facility. These women have repeated visits to the health care centre for antenatal check-up so, Counselling during this period is the key to improve the awareness and acceptance of PPIUCD in our community. Multiple counselling sessions during antenatal visits and including husband during PPFP counselling can make it easier for the women to slowly understand the process and accept PPIUCD. Women who are only counselled during postpartum period have lesser chances of accepting PPIUCD as compared to the women who are counselled during her antenatal visits as these women are exhausted with delivery process and don't have much time to make decision.
Funding: No funding sources

Conflict of interest: None declared

Ethical approval: The study was approved by the Institutional Ethics Committee

\section{REFERENCES}

1. Rutstein SO. Effects of preceding birth intervals on neonatal, infant and under-five years mortality and nutritional status in developing countries: Evidence from the demographic and health surveys. Int $\mathbf{J}$ Gynaecol Obstet. 2005;89(Suppl 1):S7-S24.

2. Zhu BP, Rolfs RT, Nangle BE, Horan JM. Effect of the interval between pregnancies on perinatal outcomes. New Engl J Med. 1999;340(8):589-94.

3. Khoshnood B, Lee KS, Wall S, Hsieh HL, Mittendorf R. Short interpregnancy intervals and the risk of adverse birth outcomes among five racial/ethnic groups in the united states. Am J Epid. 1998;148(8):798-805.

4. Cleland J, Bernstein S, Ezeh A, Faundes A, Glasier A, Innis J. Family planning the unfinished agenda. Lancet. 2006;368:1810-27.

5. Borda M, Winfrey W. Postpartum fertility and contraception: an analysis of findings from 17 countries. Baltimore Jhpiego. 2010:15-20.

6. Jakson E, Glasire A. Return of ovulation and menses in postpartum nonlactating women: a systemic review. Obstet Gynecol. 2011;117:657-62.

7. Conolly A, Thorp J, Pahel L. Effects of pregnancy and childbirth on postpartum sexual function: a longitudinal prospective study. Int Urogynecol J. 2005;16:263-67.

8. United Nations, department of economic and social affairs, population division 2015. Trends in Contraceptive Use Worldwide 2015. Available at: http://www.un.org/en/developement/desa/population/ publications/pdf/family/trendsContraceptiveUse2015 Report.pdf. Accessed on $10^{\text {th }}$ October 2018.

9. International institute for population sciences (IIPS) and ICF. 2017. National family health survey (NFHS 4) 2015-2016, IIPS; 2017:111-184.

10. Kaneshiro B, Abey T. Long term safety, efficacy and patient acceptability of intrauterine copper T-380A contraceptive device. Int J Women's Health. 2010:211-220.

11. Kathpalia SK, Mustafa MS. Awareness about postpartum insertion of intrauterine device among antenatal cases. Med $\mathrm{J}$ Armed Forces India. 2015;71(3):221-4.

12. Priya S. Postpartum intrauterine device insertion: the unfinished agenda. New Indian J Surg. 2011;2:245-7.

13. Achyut P, Mishra A, Montana L, Sengupta R, Calhoun LM, Nanda P. Integration of family planning with maternal health services: an opportunity to increase postpartum modern contraceptive use in urban Uttar Pradesh, India. J Fam Plann Reprod Health Care. 2016;42(2):107-15. 
14. Thomas D, Maluccio J. Fertility, contraceptive choice and public policy in Zimbabwe. World Bank Econ Rev. 1996;10(1)189-222.

15. Valliappan A, Dorairajan G, Chinnakali P. Postpartum intrauterine contraception device: knowledge and factors affecting acceptance among pregnant/parturient women attending a large tertiary health care centre in Puducherry, India. Int $\mathrm{J}$ Adv Med Health Res. 2017;4:69-74.

16. Nigam A, Ahmad A, Sharma A, Saith P, Batra S. Postpartum intrauterine device refusal in Delhi: reason analysed. J Obstet Gynaecol India. 2018:68(3)208-13.

17. World health organization. 2016. WHO recommendations on positive pregnancy experience. Available at: https://apps.who.int/iris/bitstream/ handle/10665/250796/9789241549912-eng.pdf.

Accessed on $24^{\text {th }}$ May 2020.

18. Cleland J, Shah IH, Daniele M. Interventions to improve postpartum family planning in low and middle-income countries: "program implications and research priorities". Studd Fam Plann. 2015;46(4):423-41.
19. Agrawal N, Gupta M, Sharma A, Arora R. Antenatal counselling as a tool to increase acceptability of postpartum intrauterine contraceptive device insertion in a tertiary care hospital. Int $\mathbf{J}$ Reprod Contracept Obstet Gynecol. 2015;4(4):1137-41.

20. Gautam R, Arya KN, Kharakwal S, Singh S, Trivedi M. Overview of immediate PPIUCD application in Bundelkhand region. J Evolution Med Dent Sci. 2014;36(3):9518-26.

21. Worku C, Assefa T, Bogale D, Girma A. Acceptability and factors associated with postpartum IUCD use among women who gave birth at bale zone health facilities, Southeast Ethiopia. Contracept Reprod Med. 2018;3:16.

Cite this article as: Raghuwanshi M, Agrawal S, Singh BK, Khatik N. Postpartum intrauterine contraceptive device: effect of antenatal versus postpartum counselling in acceptance of postpartum intrauterine contraceptive device. Int J Reprod Contracept Obstet Gynecol 2020;9:3742-8. 